\title{
RESEARCH
}

Open Access

\section{Cardamonin inhibits breast cancer growth by repressing HIF-1a-dependent metabolic reprogramming}

Jinmei Jin ${ }^{1 \dagger}$, Shuiping Qiu ${ }^{1 \dagger}$, Ping Wang ${ }^{1}$, Xiaohui Liang ${ }^{1}$, Fei Huang ${ }^{1}$, Hui Wu' ${ }^{1}$, Beibei Zhang ${ }^{1}$, Weidong Zhang ${ }^{3}$, Xinhui $\operatorname{Tian}^{3}$, Ren $\mathrm{Xu}^{2^{*}}$, Hailian Shi ${ }^{{ }^{*}}$ (I) and Xiaojun $\mathrm{Wu}^{1}$

\begin{abstract}
Background: Cardamonin, a chalcone isolated from Alpiniae katsumadai, has anti-inflammatory and anti-tumor activities. However, the molecular mechanism by which cardamonin inhibits breast cancer progression largely remains to be determined.

Methods: CCK-8 and Hoechst 33258 staining were used to detect cell growth and apoptosis, respectively. HIF-1a driven transcription was measured by luciferase reporter assay. Glucose uptake and lactate content were detected with 2-NBDG and L-Lactate Assay Kit. Cell metabolism assays were performed on Agilent's Seahorse Bioscience XF96 Extracellular Flux Analyzer. Mitochondrial membrane potential was measured with JC-1 probe. DCFH-DA was used to measure ROS level. Protein expression was detected by western blotting assay. Immunohistochemistry was performed to measure the expression of HIF-1a, LDHA and CD31 in tumor tissues.

Results: Cardamonin inhibited growth of the triple negative breast cancer cell line MDA-MB-231 in vitro and in vivo by suppressing HIF-1a mediated cell metabolism. Cardamonin inhibited the expression of HIF-1a at mRNA and protein levels by repressing the mTOR/p70S6K pathway, and subsequently enhanced mitochondrial oxidative phosphorylation and induced reactive oxygen species (ROS) accumulation. We also found that cardamonin inhibited the Nrf2-dependent ROS scavenging system which further increased intracellular ROS levels. Eventually, accumulation of the intracellular ROS induced apoptosis in breast cancer cells. In addition, cardamonin treatment reduced glucose uptake as well as lactic acid production and efflux, suggesting its function in repressing the glycolysis process.
\end{abstract}

Conclusions: These results reveal novel function of cardamonin in modulating cancer cell metabolism and suppressing breast cancer progression, and suggest its potential for breast cancer treatment.

Keywords: Cardamonin, Breast cancer, Mitochondrial oxidative phosphorylation, Reactive oxygen species, Apoptosis, Cell metabolism

\footnotetext{
*Correspondence: ren.xu2010@uky.edu; shihailian2003@163.com

${ }^{\dagger}$ Jinmei Jin and Shuiping Qiu contributed equally to this work.

${ }^{2}$ Markey Cancer Center, Department of Pharmacology and Nutritional

Sciences, University of Kentucky College of Medicine, Biopharm 553, 789 S.

Limestone, Lexington, KY 40536, USA

${ }^{1}$ Shanghai Key Laboratory of Compound Chinese Medicines, Institute of

Chinese Materia Medica, Shanghai University of Traditional Chinese Medicine,

1200 Cailun Road, Zhangjiang Hi-tech Park, Shanghai 201203, China

Full list of author information is available at the end of the article
}

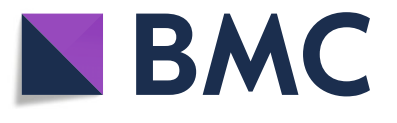

(c) The Author(s). 2019 Open Access This article is distributed under the terms of the Creative Commons Attribution 4.0 International License (http://creativecommons.org/licenses/by/4.0/), which permits unrestricted use, distribution, and reproduction in any medium, provided you give appropriate credit to the original author(s) and the source, provide a link to the Creative Commons license, and indicate if changes were made. The Creative Commons Public Domain Dedication waiver (http://creativecommons.org/publicdomain/zero/1.0/) applies to the data made available in this article, unless otherwise stated. 


\section{Background}

Breast cancer is the second leading cause of cancer death among women across the world [1]. Chemotherapy is a common therapeutic strategy for breast cancer patients. However, serious adverse effects such as digestive tract toxicity, cardiovascular system toxicity, skin toxicity, hepatotoxicity, and delayed wound healing compromise the clinical effects of current chemotherapy drugs [2]. Thus, development of new chemotherapy drugs with fewer side effects remains to be an urgent need for breast cancer treatment.

Electron leakage from mitochondrial electron transport is the main source of intracellular reactive oxygen species (ROS) [3, 4]. Although appropriate levels of ROS benefit cancer cell proliferation and growth, over-accumulation of ROS results in cell damage and apoptosis [3, 5]. Metabolic reprogramming is one of the hallmarks of cancer [6]. Different from normal cells to use mitochondrial oxidative phosphorylation (OXPHOS) for energy supply, most of breast cancer cells have increased aerobic glycolysis in both normal and hypoxia conditions, which produces energy and intermediate metabolites to support proliferation and growth [6-9]. Compared with mitochondrial OXPHOS, aerobic glycolysis generates less ROS, while promotes glutaminolysis and enhances pentose phosphate pathway (PPP) metabolism to facilitate the biosynthetic process $[10,11]$. Therefore, targeting metabolic reprogramming of cancer cells may be a promising strategy for cancer treatment.

Hypoxia-inducible factor- $1 \alpha$ (HIF-1 $\alpha$ ) is an important regulator of cell metabolism in various tumors [12]. Upon activation, HIF-1 $\alpha$ enhances aerobic glycolysis by directly inducing expressions of many cell metabolism genes, including glucose transporters (GLUTs) such as GLUT1, 3, 4, pyruvate dehydrogenase kinase 1 (PDHK1) [13], lactate dehydrogenase A (LDHA) and monocarboxylate transporters (MCTs) such as MCT1 and MCT4 [12, 14-16]. It has been shown that PI3K/PTEN/AKT and RAS/RAF/MEK/ERK pathways participate in the regulation of HIF-1 $\alpha$ expression. The PI3K/PTEN/ AKT pathway enhances translation of HIF-1 $\alpha$ in a mTOR dependent or independent manner [12, 1719]. The RAS/RAF/MEK/ERK pathway induces HIF$1 \alpha$ expression at both translational and transcriptional levels [12, 20, 21].

Cardamonin is a chalcone isolated from Alpinia katsumadai with significant anti-tumor activities in lung cancer, colon cancer, nasopharyngeal carcinoma and glioblastoma [22-31]. Cardamonin also inhibits growth of chemotherapy-resistant breast cancer cells [26]. Although cardamonin has been identified as a Wnt and NF- $\mathrm{kB}$ inhibitor [22, 29, 32], the detailed molecular mechanism by which cardamonin inhibits breast tumor growth largely remains to be determined. In the present study, we showed that cardamonin significantly inhibited the growth of breast cancer in vivo and in vitro, which is most likely mediated by reprogramming cancer metabolism through inhibition of the HIF-1 pathway. These findings may facilitate the clinical application of cardamonin in breast cancer treatment.

\section{Materials and methods \\ Cell culture}

MDA-MB-231 cells were obtained from Cell Bank, Type Culture Collection of Chinese Academy of Sciences (Shanghai, China), and maintained in DMEM medium (Gibco, Cat. No.:11965-092) supplemented with 10\% fetal bovine serum (FBS, Gibco, Cat. No.: 10099-141) and $1 \%$ penicillin \& streptomycin (Meilunbio, Cat. No.: MA0110) in a humidified incubator containing 5\% $\mathrm{CO}_{2}$ at $37^{\circ} \mathrm{C}$. MGC803 and HCT8 cells, also obtained from Cell Bank, Type Culture Collection of Chinese Academy of Sciences, were both cultured in RPMI 1640 medium (Meilunbio, Cat. No.: MA 0215). MCF7, gifted by Prof. Tu Hong from Shanghai Jiao Tong University (China), was maintained in DMEM medium supplemented with $10 \%$ FBS and $1 \%$ penicillin \& streptomycin. MCF-10A cells and BT549 cells, obtained from Zhongqiao Xinzhou Biotechnology (Shanghai, China), were cultured in special medium (Cat. No.: ZQ-1311, Zhongqiao Xinzhou Biotechnology) and RPMI 1640 medium, respectively, supplemented with $10 \%$ FBS and $1 \%$ penicillin \& streptomycin.

\section{Cell viability assay}

Cells were seeded in 96-well culture plates $\left(2.0 \times 10^{3}\right.$ cells/well) and grown overnight. After treatment with cardamonin at different concentrations for $24-72 \mathrm{~h}$, the cells were incubated with CCK-8 (Cell Counting Kit-8, DOJINDO Laboratories, Cat. No.: CK04) solution $(20 \mu \mathrm{l} /$ well) and cultured at $37^{\circ} \mathrm{C}$ for another $1 \mathrm{~h}$. Absorbance of the dissolved solutions was detected at $450 \mathrm{~nm}$ on a Thermo Scientific Varioskan Flash microplate reader (USA). The cell viability rate was calculated as follows: (absorbance of drug-treated sample/absorbance of control sample) $\times 100$.

\section{Hoechst 33258 staining}

MDA-MB-231 cells were seeded at a density of $1.5 \times 10^{5}$ cells/ml on coverslips in a 24 -well plate and allowed to adhere to the coverslips overnight. After being treated with cardamonin $(10,20$ and $40 \mu \mathrm{M})$ for $24 \mathrm{~h}$, the cells were fixed with $4 \%$ PFA for $10 \mathrm{~min}$. Then being gently rinsed with $1 \times$ PBS, the cells were stained with $10 \mu \mathrm{g} / \mathrm{ml}$ Hoechst 33258 solution for 15 min. Finally the cells were rinsed with $1 \times \mathrm{PBS}$ and the cell morphology was observed under a fluorescence microscope. 


\section{Western blotting assay}

MDA-MB-231 cells and tumor tissue homogenates were lysed in CelLytic ${ }^{\text {Tn }}$ MT Cell Lysis Reagent (Sigma, Cat. No.:C3228) containing protease and phosphatase inhibitors (Roche, Cat. No.: 04693116001, 04906837001) on ice for $30 \mathrm{~min}$. After centrifugation at $12000 \mathrm{rpm}$ for 15 min at $4{ }^{\circ} \mathrm{C}$, the supernatant was collected and subjected to $\mathrm{BCA}$ assay to determine the protein concentration. Totally $30 \mu \mathrm{g}$ proteins from each samples were separated by SDS-PAGE (10\%) and transferred onto PVDF membrane. Afterwards, the membranes were blocked with $0.5 \%$ BSA for $1 \mathrm{~h}$ and incubated with primary antibodies against GAPDH (CST, Cat. No.:5174S, 1:1000), HIF-1 $\alpha$ (BD, Cat. No.: 81095, 1:1000), PDHK1 (CST, Cat. No.: 3820 T, 1:1000), LDHA (CST, Cat. No.: c28H7, 1:1000), LDHB (Abcam, Cat. No.: ab85319, 1:1000), p-PI3K (CST, Cat. No.: Y458, 1:1000), PI3K (CST, Cat. No.: 4257S, 1:1000) p-AKT(CST, Cat. No.: S473, 1:1000), AKT (Abcam, Cat. No.: ab32505, 1:1000), p-mTOR (Abcam, Cat. No.: ab109268, 1:1000), mTOR (Abcam, Cat. No.: ab32028, 1:1000), P70S6K (CST, Cat. No.: 2903, 1:1000), p-p70S6K (Abcam, Cat. No.: 9234S, 1: 1000), Cleaved-caspase3 (CST, Cat. No.: 9664S, 1:1000), Bcl2 (CST, Cat. No.: 50E3, 1:1000), Bax (CST, Cat. No.: 2772S, 1:1000), Nrf2 (Santa Cruz, Cat. No.: sc-722, 1: 1000), NQO1 (Santa Cruz, Cat. No.: sc-32,793, 1:1000), and HO-1 (Santa Cruz, Cat. No.: sc-136,960, 1:1000) overnight at $4{ }^{\circ} \mathrm{C}$. After being washed with $1 \times \mathrm{TBST}$, the membranes were incubated with respective secondary antibodies conjugated with horseradish peroxidase for 1 $\mathrm{h}$ at room temperature. The protein bands were visualized with Immobilon ${ }^{\text {Tx }}$ Western Chemiluminescent HRP Substrate (Millipore Corporation, Cat. No.: WBKLS0500), and the images were captured on the visualization instrument Tanon-5200 (Tanon, China).

\section{Real-time quantitative PCR}

Total RNA from MDA-MB-231 cells were extracted by using TRIzol Reagent (Ambion, REF: 15596018). cDNA was synthesized with Revert Aid First Strand cDNA Synthesis Kit (Thermo, Cat. No.: K1622). Real-time quantitative PCR was performed by using SYBR reagent (VazymE, L/N 7E141I7, Cat. No.: Q111-02) on Quant Studio 6 Flex System (Life technologies, Cat. No.: 20170777). Quantification of target genes was determined by the $2^{-\Delta \Delta \mathrm{Ct}}$ method. And the relative expression of individual genes was normalized to that of GAPDH in the same sample. The sequences for forward $(\mathrm{F})$ and reverse $(\mathrm{R})$ primers used were listed as follows: HIF- $1 \alpha$, F: 5 '-AGCCGAGGAAGAACTATGA-3', R: 5' -TTTGATGGGTGAGGAATG-3'; PDHK1, F: 5' GATGTGAATGGGCAGTTAGT-3', R:5'-AGGAATAG TGGGTTAGGTGAG-3'; LDHA, F: 5' - TGGAGTGGAA TGAATGTTG-3', R: 5' - GATGTGTAGCCTTTGAG TTTG-3'; LDHB, F: 5' - GAAGGAGGAAGAAGCACA-3',
R: 5'- GCACAAGGACAAGTAGGG-3';GAPDH, F, 5'GCACCGTCAAGGCTGAGAAC-3'， R: 5' - TGGTGA AGACGCCAGTGGA-3.

\section{Mitochondrial membrane potential (MMP) measurement} MMP of MDA-MB-231 cells were measured by using fluorescent probe JC-1 (Santa Cruz, Cat. No.: sc-364, 116). The cells treated with cardamonin $(20 \mu \mathrm{M})$ for different time points were rinsed with HBSS (Gibco, Cat. No.: $14025-092)$ and incubated with JC-1 $(10 \mu \mathrm{M})$ at $37^{\circ} \mathrm{C}$ for $30 \mathrm{~min}$. Afterwards, the cells were rinsed with HBSS once again. Fluorescent intensity of the JC-1 monomers and aggregates was detected under different conditions (Ex $(\lambda) 485 \mathrm{~nm}, \operatorname{Em}(\lambda) 530 \mathrm{~nm}$ for monomers; $\operatorname{Ex}(\lambda) 530 \mathrm{~nm}, \operatorname{Em}(\lambda) 590 \mathrm{~nm}$ for aggragates) on a microplate reader (Varioskan Flash, Thermo Scientific, UAS). Fluroscent images of the cells were taken under a fluorescent microscope (IX81, Olympus, Japan).

\section{Glucose uptake assay}

Glucose uptake ability of MDA-MB-231 cells was evaluated by using the fluorescent glucose 2-NBDG (Thermo Fisher Scientific, Cat. No.: N13195). MDA-MB-231 cells seeded in 96-well plates were cultured in DMEM medium without glucose or carbon sources. After being treated with cardamonin $(20 \mu \mathrm{M})$ for 3 and $6 \mathrm{~h}$, respectively, the cells were gently rinsed with HBSS and incubated with $100 \mu \mathrm{M}$ 2-NBDG at $37^{\circ} \mathrm{C}$ for $30 \mathrm{~min}$. Consequently, the cells were rewashed with HBSS. Fluorescent intensity of the cells was detected on a microplate reader $(\operatorname{Ex}(\lambda) 465 \mathrm{~nm}$; $\operatorname{Em}(\lambda) 540 \mathrm{~nm})$. Meanwhile, after being treated with cardamonin $(10,20,40$, $80 \mu \mathrm{M})$ for $6 \mathrm{~h}$, the glucose uptake of MDA-MB-231 cells was also measured according to the above method.

\section{Lactate content measurement}

Lactate, one of the end-products of aerobic glycolysis, can change the tumor microenvironment and have an impact on cancer-associated cells [10]. Intracellular and extracellular lactate contents of MDA-MB-231 cells were determined by using the L-Lactate Assay Kit (Cayman, Bath: 0521418, USA). MDA-MB-231 cells were cultured in the DMEM basic medium supplemented with $10 \%$ FBS and treated with cardamonin $(20 \mu \mathrm{M})$ for $24 \mathrm{~h}$. Then, the cells were cultured in DMEM basic medium containing $0.5 \%$ FBS for another $4 \mathrm{~h}$. The cell pellet and culture medium were collected for lactate content measurement according to the manufacturer's instructions.

\section{ROS measurement}

The ROS level was measured according to the method described previously [33] with some modifications. Intracellular ROS level in MDA-MB-231 cells was detected by $2^{\prime}, 7^{\prime}$-dichlorodihydrofluorescein (DCFH), which is 
oxidized into fluorescent dichlorofluorescein (DCF) in the presence of ROS. MDA-MB-231 cells were cultured in the 96-well plates at a density of $1 \times 10^{5} \mathrm{cells} / \mathrm{ml}$ in DMEM medium containing 10\% FBS. After being treated with cardamonin $(20 \mu \mathrm{M})$ for 2,4 , and $6 \mathrm{~h}$, respectively, the cells were gently washed with HBSS followed by the incubation with $20 \mu \mathrm{M}$ DCFH at $37^{\circ} \mathrm{C}$ for $30 \mathrm{~min}$. The dye was then removed and replaced with fresh HBSS. Fluorescence of the cells was measured immediately on a microplate reader $(\operatorname{Ex}(\lambda) 485 \mathrm{~nm}$; $\operatorname{Em}(\lambda)$ $535 \mathrm{~nm}$ ). Meanwhile, after being treated with cardamonin $(10,20,40$ and $80 \mu \mathrm{M})$ for $6 \mathrm{~h}$, intracellular ROS level in MDA-MB-231 cells was also measured according to the above method.

\section{Cell metabolism assays}

The Mito Stress Test Kit (Agilent, Cat. No.: 103015100) was used to measure the oxygen consumption rate (OCR). The Glycolytic Rate Assay Kit (Agilent, Cat. No: 103344-100) was used for measuring the glycolytic proton efflux rate (GlycoPER). The Agilent Seahorse XF Real-Time ATP Rate Assay Kit (Agilent, Cat. No.: 103592-100) was used to detect the ATP production rates of mitochondrial oxidative phosphorylation and glycolysis, respectively. Before metabolism measurement, the probe plate was hydrated with HPLC grade water in a $\mathrm{CO}_{2}$-free incubator. The assay phenol red-free solution containing $10 \mathrm{mM}$ glucose, $2 \mathrm{mM}$ glutamine, $1 \mathrm{mM}$ pyruvate and $5 \mathrm{mM}$ HEPES was kept in a $37{ }^{\circ} \mathrm{C} \mathrm{CO}_{2}$-free incubator to maintain the $\mathrm{pH}$ value. Then the HPLC grade water in the hydration plate was replaced with calibration solution and kept in a $37{ }^{\circ} \mathrm{C} \mathrm{CO}_{2}$-free incubator. MDA-MB-231 cells were seeded into XF96 cell culture microplates (Seahorse Bioscience) at the density of 5000 cells/well (for measurement of OCR and GlycoPER) or 7500 cells/well (for measurement of ATP production rates of oxidative phosphorylation and glycolysis), and allowed to adhere to plate overnight. Then the cells were incubated with cardamonin $(20 \mu \mathrm{M})$ for 3, 6 and $12 \mathrm{~h}$, and the cell culture medium was replaced with phenol red-free assay solution and placed in a $37{ }^{\circ} \mathrm{C}$ $\mathrm{CO}_{2}$-free incubator for $1 \mathrm{~h}$. Finally, OCR, GlycoPER and ATP production rates of mitochondrial oxidative phosphorylation and glycolysis were determined and analyzed on the Agilent's Seahorse Bioscience XF96 Extracellular Flux Analyzer (Agilent Technologies) according to the manufacturer's instructions and protocols (Seahorse Bioscience, North Billerica, MA, USA).

For the detection of GlycoPER value, Rot/AA (inhibitors of mitochondrial electron transport chain) and 2-deoxy-D-glucose (2-DG, inhibitor of glycolysis) were added according to the manufacturer's instructions and protocols (Seahorse Bioscience, North Billerica, MA, USA).
For the measurement of OCR value, oligomucin, FCCP, and Rot/AA, respectively, were added according to the manufacturer's instructions and protocols (Seahorse Bioscience, North Billerica, MA, USA).

For the determination of ATP production rates of mitochondrial oxidative phosphorylation and glycolysis, oligomycin and a mix of rotenone and antimycin A were added according to the manufacturer's instructions and protocols (Seahorse Bioscience, North Billerica, MA, USA).

\section{HIF-1a overexpression induced by $\mathrm{CoCl}_{2}$}

According to previous studies [34, 35], in this study, briefly, HIF- $1 \alpha$ accumulation was induced by $100 \mu \mathrm{M}$ $\mathrm{CoCl}_{2}$ (Cobalt chloride, Sigma-Aldrich, Cat. No.: 60818) for $6 \mathrm{~h}$ in MDA- MB-231 cells.

\section{Transient transfection for overexpression of PDHK1}

GV230-PDHK1 plasmids or GV230 plasmids were purchased from Shanghai Genechem (Shanghai, China). Briefly, MDA-MB-231 cells at $60-80 \%$ confluency, was transiently transfected with GV230-PDHK1 plasmids or GV230 plasmids using NEOFECT DNA transfection reagent (Neofect Beijing Biotech, China). Results of western blotting assay (Fig.5g) demonstrated that PDHK1 overexpression was successfully induced after $32 \mathrm{~h}$ of transfection in MDA-MB-231 cells. In further study, MDA-MB-231 cells transiently transfected with GV230PDHK1 plasmids or GV230 plasmids for $24 \mathrm{~h}$ were treated with or without cardamonin $(20 \mu \mathrm{M})$ for $24 \mathrm{~h}$. Then the cells were subjected to CCK- 8 assay.

\section{Luciferase reporter assay}

Luciferase reporter construct containing three HRE was purchased from Addgene (26731). HRE-luciferase reporter plasmid and Renilla luciferace vector were transiently transfected into HEK293 cells. The cells were treated with cardamonin ( 20 and $40 \mu \mathrm{M})$ for $24 \mathrm{~h}$. Then the cells were harvested and subjected to luciferase activity assay by using Dual-Luciferase ${ }^{\mathrm{R}}$ Reporter Assay system (Promega, Cat. No. E1910).

\section{Animal treatment}

Female nude mice, 4-week-old, were purchased from Shanghai Slake Experimental Animal Co., Ltd. and kept under SPF level conditions. All animal experiments were carried out in accordance with the protocol approved by the Animal Ethics Committee in Shanghai University of Traditional Chinese Medicine (SHUTCM), which complies with international rules and policies for laboratory animal use and care as founded in the European Community guidelines (EEC Directive of 1986; 86/609/EEC). All animal experiments were approved by the institutional Ethics Committee of SHUTCM (SZY201704012). 
After habituation for a week, the mice were inoculated subcutaneously with MDA-MB-231 cells $(1.0 \times$ $10^{7}$ cells in $200 \mu \mathrm{L}$ PBS per mouse). When the tumor grew to $50 \mathrm{~mm}^{3}$, the nude mice were randomly divided into three groups, namely control group, cardamonin group and 5-Fu group. The mice in control group and cardamonin group were intraperitoneally injected with physiological saline and cardamonin (3 $\mathrm{mg} / \mathrm{kg}$ ), respectively, once a day. But the mice in 5$\mathrm{Fu}$ group were intraperitoneally injected with 5 - Fu $(50 \mathrm{mg} / \mathrm{kg})$ twice a week. Body weight and tumor size of the nude mice were recorded every 3 days. The size of the tumor was calculated according to the formula: [length $\left.\times(\text { width })^{2}\right] / 2$. Four weeks after the drug administration, the nude mice were sacrificed and the tumor tissues were isolated for further analysis.

\section{Hematoxylin and eosin (H\&E) staining}

H\&E staining was conducted to assess the pathological change of tumor tissues according to the procedure described previously [36]. And the images were captured with microscope (Olympus, BX61VS).

\section{Immunohistochemistry (IHC) analysis}

The IHC experiments were performed according to the specific operations described previously [37-41]. In brief, tumor tissue sections, $5 \mu \mathrm{m}$ thick, were deparaffinized with xylen and rehydrated in gradient alcohol (anhydrous, 95, 75\%). After being washed three times in PBS, the sections were incubated with $0.3 \% \mathrm{H}_{2} \mathrm{O}_{2}$ for $10 \mathrm{~min}$ to block the endogenous peroxidase. Then the sections were placed in sodium citrate antigen retrieval solution for $10 \mathrm{~min}$ in microwave oven. Thereafter, they were incubated with $10 \%$ goat serum blocking solution for 30 min followed by the incubation with primary antibodies against HIF- $1 \alpha$, LDHA and CD31 overnight at $4{ }^{\circ} \mathrm{C}$. Subsequently, the slices were incubated with secondary antibody conjugated with horseradish peroxidase for $1 \mathrm{~h}$ at room temperature. After DAB coloring reaction, the images were captured by Olympus VS120 Virtual Slide Scanner. Positive expressions of target proteins were displayed in brown color, and the cell nuclei were stained in blue color by hematoxylin. Five randomly selected fields were evaluated using a $\mathrm{BH} 2$ microscope (Olympus, Tokyo, Japan) equipped with a Nikon 4500 digital camera. The area and optical density (OD) of HIF-1 $\alpha$, LDHA and CD31 in each field were processed by the computer-aided automatic image analysis system (Qiu Wei, Shanghai, China). The IHC index was calculated as the average integral OD: [(positive area $\times \mathrm{OD}) /$ total area].

\section{Statistical analysis}

All data were presented as mean \pm standard deviation. Differences among groups were analyzed by one-way ANOVA analysis of variance with Dunnett's test or the Student's $t$-test using GraphPad 5.0 software (La Jolla, CA, USA). The value of $P<0.05$ was considered statistically significant.

\section{Results \\ Cardamonin inhibits cell viability and promotes apoptosis of MDA-MB-231 cells}

To verify the inhibitory activity of cardamonin in tumor growth [22-31], we treated a panel of cancer lines with cardamonin in culture. Treatment with cardamonin $(20 \mu \mathrm{M})$ for $48 \mathrm{~h}$ significantly inhibited cell viability of HCT8 (human colorectal cancer line) by $24.41 \%$, MGC803 (human gastric cancer cell line) by $28.68 \%$, MDA-MB-231 (human triple negative breast cancer (TNBC) cell line) by 40.93\%, MCF-7 (human ER positive breast cancer cell line) by $21.83 \%$, BT 549 (human TNBC cell line) by $85.70 \%$ and 4 T1 cells (mouse TNBC cell line) by $10.78 \%$, but had little effect on cell viability of MCF-10A cells (human non-cancer mammary epithelial cell line) (Fig. 1a). As TNBC is an aggressive subtype of breast cancer with poor prognosis and has high metastasis and relapse rates after first-line treatment [42], we further investigated how cardamonin reduced viability of MDA-MB-231 cells. The $\mathrm{IC}_{50}$ values of cardamonin on MDA-MB-231 cells for $24 \mathrm{~h}, 48 \mathrm{~h}$ and $72 \mathrm{~h}$, were $52.885 \mu \mathrm{M}, 33.981 \mu \mathrm{M}$ and $25.458 \mu \mathrm{M}$, respectively (Fig. $1 \mathrm{~b})$. We found that treatement with cardamonin (20 and $40 \mu \mathrm{M})$ induced chromatin condensation and nuclear shrinkage or fragmentation (Fig. 1c). Cardamonin $(20 \mu \mathrm{M})$ also reduced protein levels of Bcl-2, while increased protein levels of Bax and cleaved caspase 3 in MDA-MB-231 cells (Fig. 1d). These results indicated that cardamonin treatment induced apoptosis in MDAMB-231 cells.

Cardamonin also significantly inhibited cell viability of BT549 cells, and the $\mathrm{IC}_{50}$ values for the treatment of 24 $\mathrm{h}$ and $48 \mathrm{~h}$, were $40.627 \mu \mathrm{M}$ and $8.598 \mu \mathrm{M}$, respectively. The $\mathrm{IC}_{50}$ values of cardamonin on MCF7 cells for $24 \mathrm{~h}$ and $48 \mathrm{~h}$, were $58.568 \mu \mathrm{M}$ and $46.803 \mu \mathrm{M}$, respectively (Additional file 1: Figure S1).

\section{Cardamonin inhibits expression of HIF-1a and its target genes in MDA-MB-231 cells}

HIF-1 $\alpha$ over-expression is associated with advanced cancer progression and poor clinical outcomes in breast cancer patients $[43,44]$. Activation of the HIF- $1 \alpha$ pathway induces expression of many metabolism-related target genes such as PDHK1 and LDHA, which enhances glycolysis but reduces mitochondrial OXPHOS [42]. Using the HRE luciferease reporter construct that 


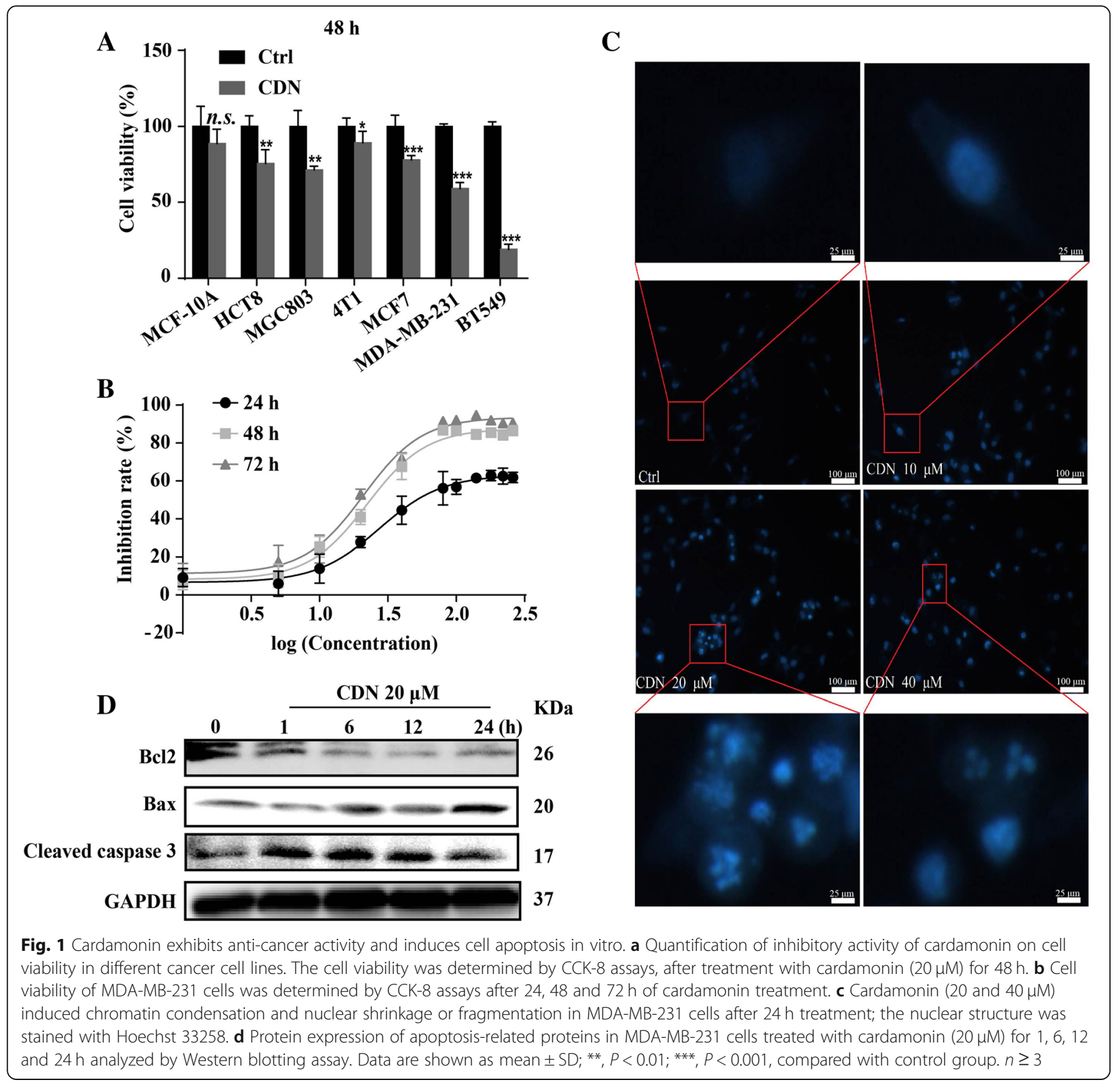

contains three hypoxia response elements (HRE), we showed that treatment with cardamonin significantly reduced HIF- $1 \alpha$ driven transcription (Fig. 2a). Protein and mRNA levels of HIF- $1 \alpha$ were downregulated in cardamonin treated cells under both normoxia and hypoxia conditions (Fig. 2b and c). Importantly, cardamonin $(20 \mu \mathrm{M})$ treatment significantly inhibited transcription of HIF- $1 \alpha$ target genes PDHK1 and LDHA (Fig. 2d). The protein levels of PDHK1 and LDHA were also reduced in cardamonin treated cells (Fig. 2e). Cardamonin treatment significantly inhibited the protein expressions of HIF- $1 \alpha$ and PDHK1 in BT549 cells, but had no significant effect on protein levels of LDHA and LDHB
(Additional file 1: Figure S3a-b). Interestingly, cardamonin treatment enhanced protein expression of HIF- $1 \alpha$, but reduced protein expression of PDHK1 in MCF7 cells (Additional file 1: Figure S3e-f), suggesting that other targets may mediate the inhibitory activity of cardamonin in MCF7 cells.

\section{Cardamonin induces metabolic reprogramming in breast} cancer cell before apoptosis occurring

To determine function of cardamonin in cell metabolism, we first used JC-1 to examine the mitochondrial membrane potential in MDA-MB-231 cells. A reduction of the mitochondrial membrane potential was detected 


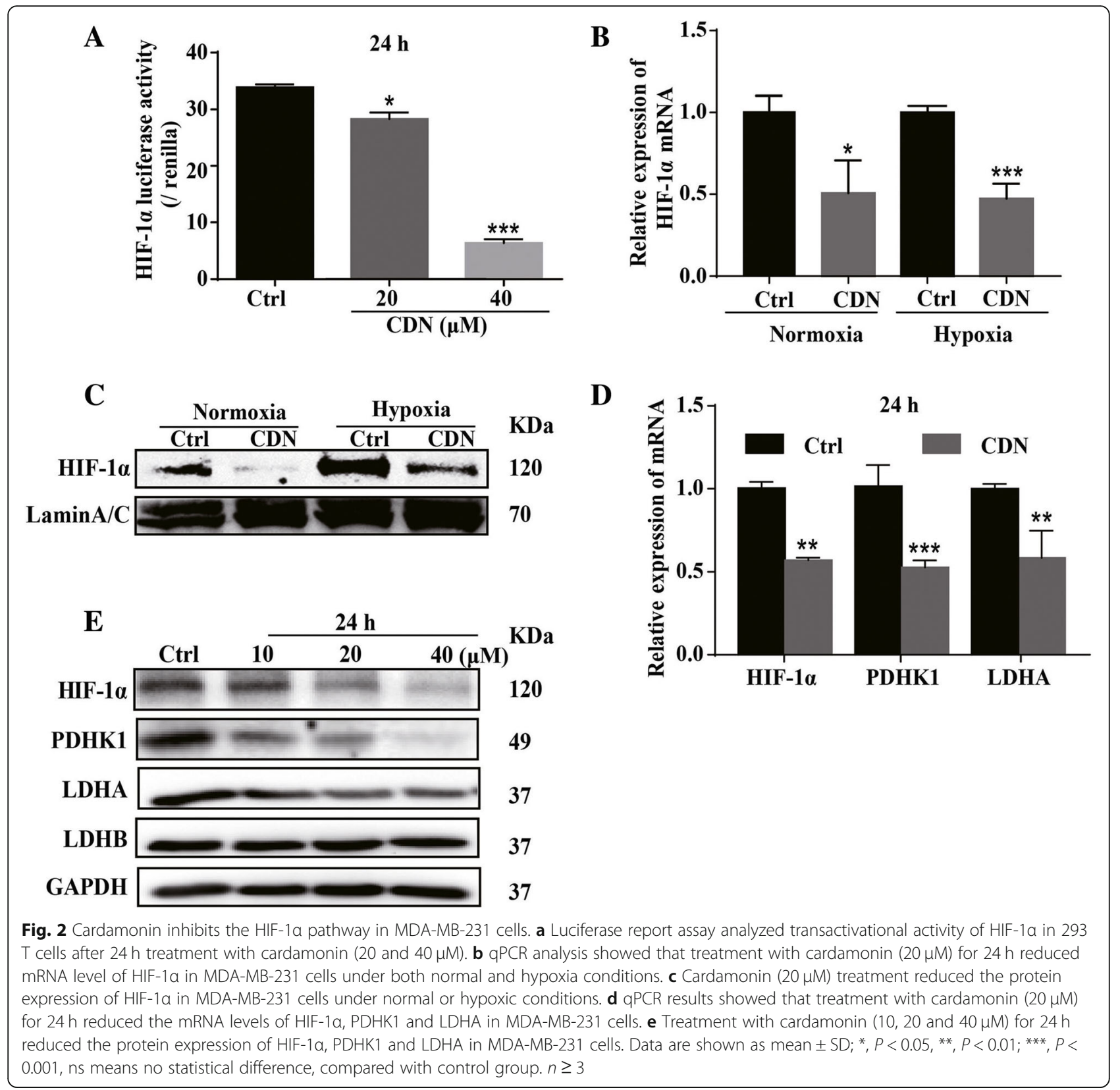

after cardamonin $(20 \mu \mathrm{M})$ treatment for $9 \mathrm{~h}$ (Fig. 3a and b). Consistent with the decreased mitochondrial membrane potential, the cell viability was significantly decreased as early as $9 \mathrm{~h}$ after treatment (Fig. 3c). Next, we used fluorescent glucose 2-NBDG to measure glucose uptake in MDA-MB-231 cells. After $6 \mathrm{~h}$ treatment with cardamonin, glucose uptake was significantly decreased in MDA-MB-231 cells (Fig. 3d and e). Intracellular and extracellular L-lactate concentrations were also significantly decreased (Fig. 3f), indicating that cardamonin reduced Llactate production and efflux. Results from the oxygen consumption rate (OCR) and extracellular acidification rate (ECAR) demonstrated that cardamonin $(20 \mu \mathrm{M})$ greatly enhanced mitochondrial OXPHOS, as evidenced by increased basal respiration, maximal respiration and spare respiratory capacity, as early as $3 \mathrm{~h}$ after treatment (Fig. $3 \mathrm{~g}$ and $h$ ). However, the basal PER and glyco-PER were significantly reduced at $12 \mathrm{~h}$ after cardamonin treatment (Fig. 3i and j), suggesting that the decrease of glycolytic rate was after the increase of mitochondrial OXPHOS. Interestingly, protein levels of HIF- $1 \alpha$ and PDHK1 but not LDHA and LDHB, were significantly down-regulated at $6 \mathrm{~h}$ after cardamonin treatment (Fig. 3k-l). Same treatment also increased the oxygen consumption rate (OCR) in BT549 cells (Additional file 1: Figure S2a-b) and MCF7 cells (Additional file 1: Figure S2h-i). The basal PER and glyco-PER were 
A
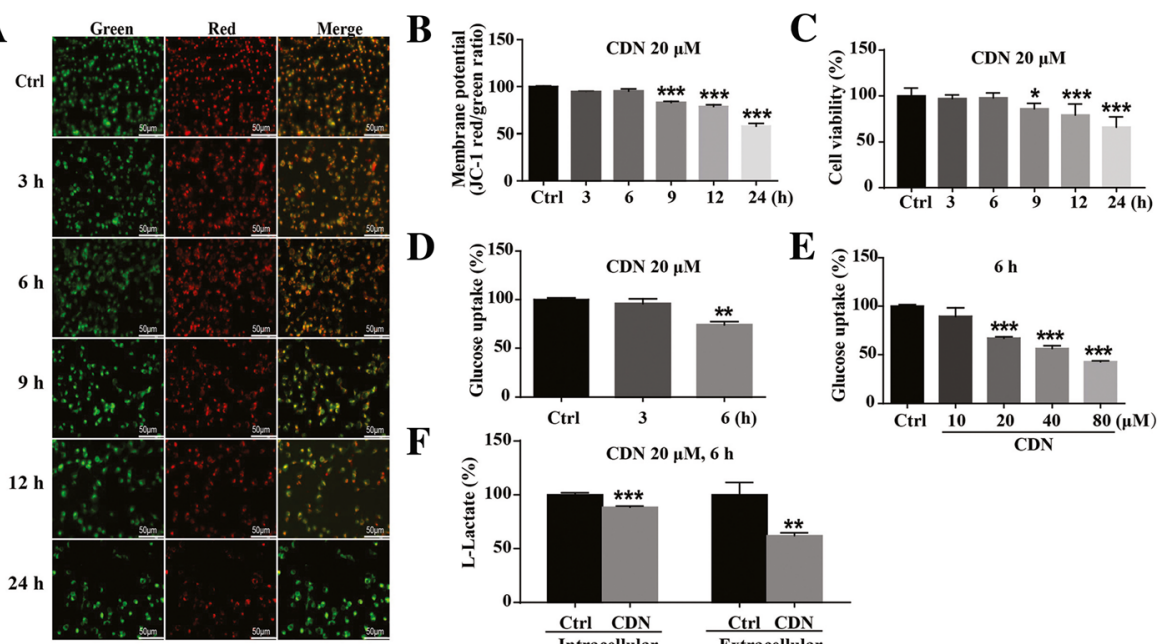

D

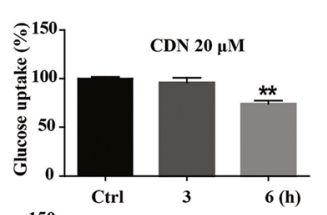

F

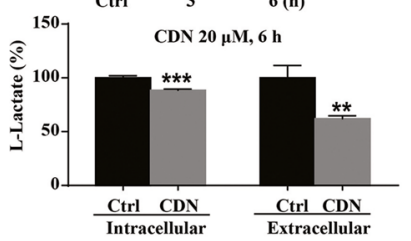

$\mathbf{E}$

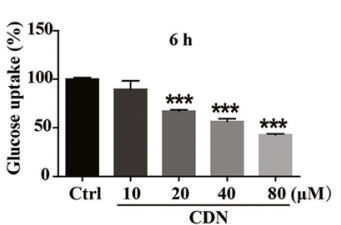

\section{G}

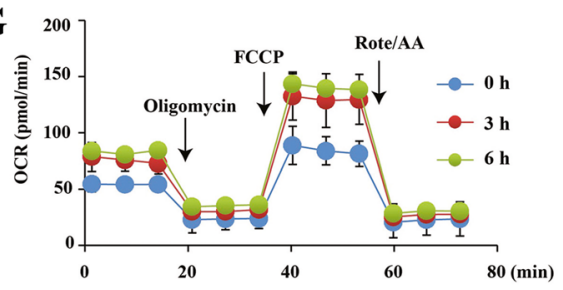

I



K

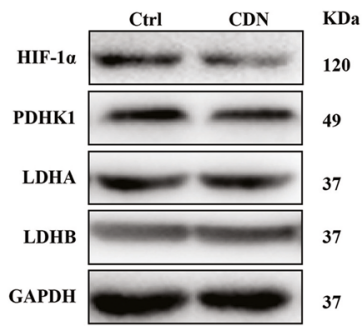

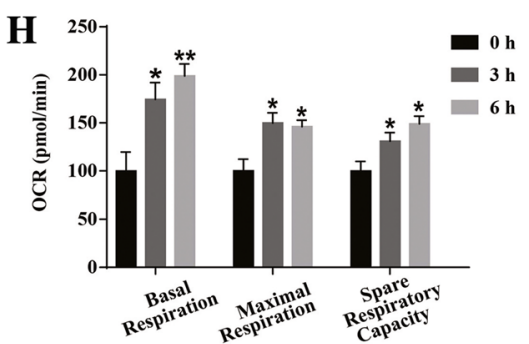

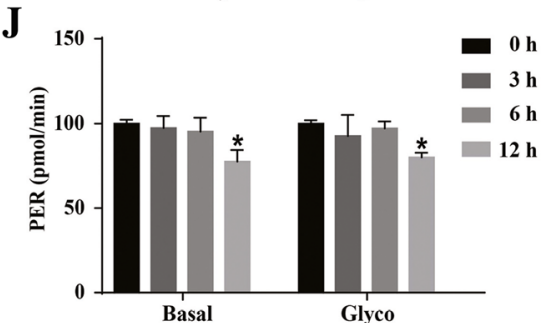

L

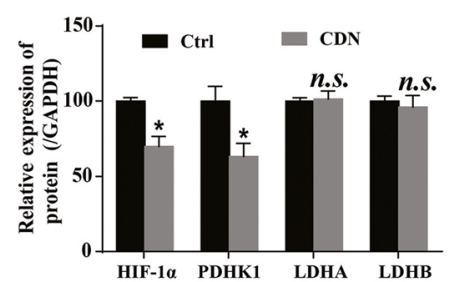

Fig. 3 Cardamonin induces metabolic reprogramming in MDA-MB-231 cells before apoptosis occurring. $\mathbf{a}$, b Cardamonin (20 $\mu \mathrm{M})$ treatment decreased mitochondrial membrane potential (MMP) in MDA-MB-231 cells; the reduction of MMP was detected by JC-1 (10 $\mu \mathrm{M})$ at $9 \mathrm{~h}$ after treatment. c CCK analysis showed that cardamonin $(20 \mu \mathrm{M})$ inhibited cell viability in MDA-MB-231 cells at $9 \mathrm{~h}$ after treatment. d, e Treatment with cardamonin (20,40 and $80 \mu \mathrm{M})$ for $6 \mathrm{~h}$ decreased glucose uptake in MDA-MB-231 cells in a dose-dependent manner. $\mathbf{f}$ Cardamonin $(20 \mu \mathrm{M})$ treatment for $6 \mathrm{~h}$ decreased intracellular and extracellular lactate levels of MDA-MB-231 cells. $\mathbf{g}$, $\mathbf{h}$ Treatment with cardamonin $(20 \mu \mathrm{M})$ for 3 and $6 \mathrm{~h}$ significantly enhanced OCR in MDA-MB-231 cells. OCR and GlycoPER were detected by the Agilent's Seahorse Bioscience XF96 Extracellular Flux Analyzer. $\mathbf{i}, \mathbf{j}$ Cardamonin $(20 \mu \mathrm{M})$ treatment for $12 \mathrm{~h}$ reduced glyco-PER of MDA-MB-231 cells. $\mathbf{k}$, I Treatment with cardamonin $(20 \mu \mathrm{M})$ for $6 \mathrm{~h}$ significantly reduced protein expression of HIF-1a and its metabolism related target genes. Data are shown as mean \pm SD; ${ }^{*} P<0.05,{ }^{* *}, P<0.01$; ${ }^{* *}, P<0.001$, compared with control. $n \geq 3$. Scale bar, $50 \mu \mathrm{m}$ 
significantly reduced in BT549 cells (Additional file 1: Figure S2c-d) and MCF7 cells (Additional file 1: Figure S2j-k) at $6 \mathrm{~h}$ after cardamonin treatment.

\section{Cardamonin treatment elevates ROS levels in MDA-MB- 231 cells}

Mitochondrial OXPHOS generates significant amount of ATP, and ROS is a by-products of this process. Cardamonin treatment $(20 \mu \mathrm{M})$ for $4 \mathrm{~h}$ elevated ROS levels in a dose-dependent manner (Fig. 4a and b). We also found that ATP production from mitochondria was enhanced by cardamonin $(20 \mu \mathrm{M})$ (Fig. $4 \mathrm{c})$; however, ATP production from glycolysis was decreased as late as $12 \mathrm{~h}$ after cardamonin treatment (Fig. 4d).

$\mathrm{Nrf2}$, a stress-response transcription factor, regulates expression of antioxidant defense genes such as HO-1 and NQO1 by binding to anti-oxidant response elements (AREs) in promoter regions in the stress condition [5, 45-47]. Thus, activation of the Nrf2 defense system mitigates ROS accumulation [48]. Therefore, we asked whether the ROS scavenging system contributes to the cardamonin-induced ROS accumulation. The protein levels of Nrf2, HO-1 and NQO-1 were significantly reduced after cardamonin treatment for $6 \mathrm{~h}$ (Fig. $4 \mathrm{e}$ and f), suggesting that Nrf2 antioxidant pathway is a potential target of cardamonin that contributes to the ROS accumulation. Similar results were also obtained in BT549 (Additional file 1: Figure S2e-g) and MCF7 cells (Additional file 1: Figure S2l-n).

\section{Activation of HIF-1a pathway abolishes effects of} cardamonin on mitochondrial OXPHOS and cell viability in MDA-MB-231 cells

To determine whether the HIF- $1 \alpha$ pathway mediated cardamonin's function in regulating cell metabolism


Fig. 4 Cardamonin enhances ROS accumulation and reduces protein expression of Nrf2, NQO1 and HO-1. a DCFH-DA analysis showed that treatment with cardamonin $(20 \mu \mathrm{M})$ for 4 and $6 \mathrm{~h}$ increased ROS accumulation in MDA-MB-231 cells. b Treatment with cardamonin $(20,40$ and $80 \mu \mathrm{M})$ for $6 \mathrm{~h}$ increased ROS accumulation in MDA-MB-231 cells. c Treatment with cardamonin for 3, 6 and $12 \mathrm{~h}(20 \mu \mathrm{M})$ increased ATP production of mitochondrial oxidative phosphorylation in MDA-MB-231 cells. The ATP production was detected by the Agilent's Seahorse Bioscience XF96 Extracellular Flux Analyzer. d Treatment with cardamonin $(20 \mu \mathrm{M})$ decreased ATP production of glycolysis in MDA-MB-231 cells at $12 \mathrm{~h}$. e, $\mathbf{f}$ Treatment with cardamonin $(20 \mu \mathrm{M})$ for 3, 6 and $9 \mathrm{~h}$ reduced the protein expression of Nrf2, NQO1 and HO-1 in MDA-MB-231 cells. Data are shown as mean \pm SD; ${ }^{*}, P<0.05,{ }^{* *}$, $P<0.01 ;{ }^{* * *}, P<0.001$, ns means no statistical difference, compared with control. $n \geq 4$ 
and viability, we performed rescue experiment by treating MDA-MB-231 cells with $\mathrm{CoCl}_{2}$. Treatment with $\mathrm{CoCl}_{2}(100 \mu \mathrm{M})$ increased protein levels of HIF$1 \alpha$ and induced PDHK1 expression in MDA-MB-231 cells. Importantly, $\mathrm{CoCl}_{2}$ treatment reversed the inhibitory effect of cardamonin on the protein expression of HIF- $1 \alpha$ and PDHK1 (Fig. 5a). $\mathrm{CoCl}_{2}$ stimulation also counteracted the increased mitochondrial OXPHOS induced by cardamonin (Fig. $5 \mathrm{~b}$ and c). Consistent with the above results, ROS production and accumulation were suppressed by $\mathrm{CoCl}_{2}$ in cardamonin-treated cells; the cell viability was also rescued
(Fig. 5d and e). NAC (N-acetyl-cysteine, ROS scavenger; $5 \mathrm{mM}$ ) abolished the inhibitory effect of cardamonin on cell viability of MDA-MB-231 cells (Fig. 5f). To further confirm whether the downregulation of HIF- $1 \alpha$ target genes mediated the inhibitory effect of cardamonin, we introduced the PDHK1 plasmid into MDA-MB-231 cells. We found that PDHK1 overexpression increased the cell viability of cardamonintreated MDA-MB-231 cells (Fig. 5g and h). Similar results were also obtained in BT549 (Additional file 1: Figure S3c-d) and MCF7 cells (Additional file 1: Figure $\mathrm{S} 3 \mathrm{~g}-\mathrm{h}$ ).

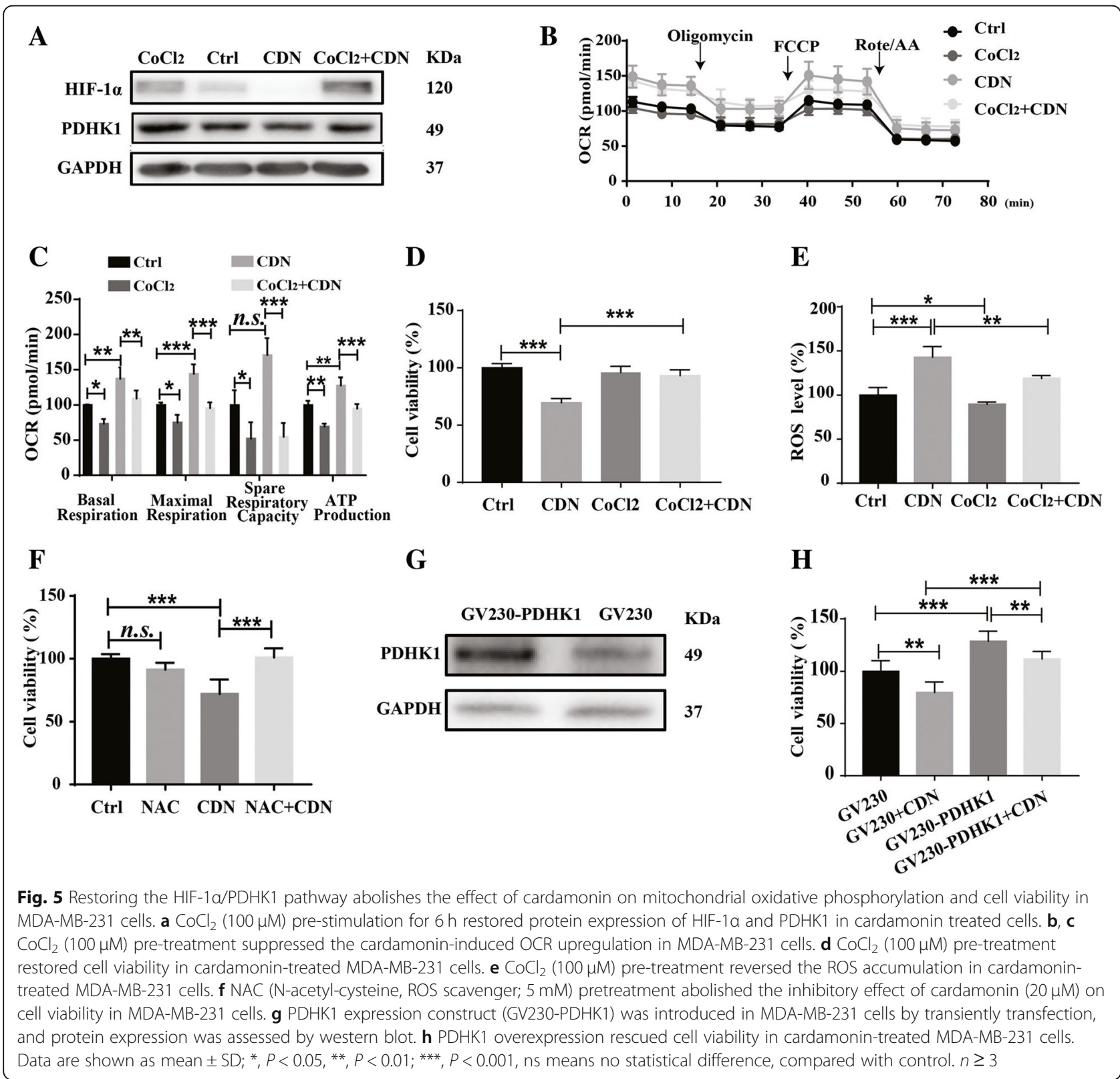


$\mathrm{mTOR} / \mathrm{p} 70 \mathrm{~S} 6 \mathrm{~K}$ pathway is the target of cardamonin to inhibit the HIF-1a pathway

We found that cardamonin treatment $(20 \mu \mathrm{M})$ reduced the protein expression of p-PI3K, p-Akt, p-mTOR and p-P70S6K in MDA-MB-231 cells in a time-dependent manner (Fig. 6a). Cardamonin treatment also decreased protein levels of p-PI3K, p-Akt, p-mTOR and p-P70S6K in a dose-dependent manner (Fig. 6b). However, at the early time points such as $0.5 \mathrm{~h}$ and $1 \mathrm{~h}$, protein levels of p-mTOR and p-P70S6K but not p-PI3K, were significantly reduced in cardamonin-treated cells (Fig. 6c). These results suggested that the mTOR/P70S6K pathway may be upstream of the HIF-1 $\alpha$ pathway in response to cardamonin treatment. Importantly, enhancing mTOR activity with MHY1485 rescued protein expression of HIF- $1 \alpha$ and PDHK1 in cardamonin-treated MDA-MB-231 cells (Fig. 6d-e). Pretreatment with mTOR activator also attenuated the inhibitory effect of cardamonin on cell viability (Fig. 6f). These results indicate that cardamonin inhibited the HIF-1 $\alpha$ pathway and cell viability through the mTOR/P70S6K pathway in MDA-MB-231 cells.
Cardamonin inhibits tumor growth and protein expression of HIF-1a in the MDA-MB-231 xenograft model

To verify the inhibitory effect of cardamonin on breast cancer growth in vivo, we performed drug treatment experiment with the MDA-MB-231 xenograft model. Cardamonin or 5-Fu administered by intraperitoneal injection significantly inhibited tumor growth in vivo compared with the control group (Fig. 7a, b and c). 5$\mathrm{Fu}$ and cardamonin had little effect on the body weight of nude mice (Fig. 7d). Furthermore, the increased protein levels of cleaved caspase 3 and Bax were upregulated in the cardamonin-treated group, while protein expression of $\mathrm{Bcl} 2$ and the ratio of $\mathrm{Bcl} 2$ / Bax were reduced (Fig. 7e and f).

$H \& E$ staining results showed that tumor cells appeared necrotic and the cytoplasmic ratio of tumor cells were decreased after cardamonin treatment (Fig. $7 \mathrm{~g})$. To determine whether cardamonin inhibited the HIF- $1 \alpha$ pathway in vivo, we assessed HIF- $1 \alpha$ protein levels and its downstream targets in tumor tissues. IHC and western blot results showed that cardamonin




A

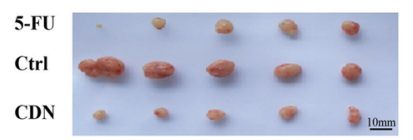

D

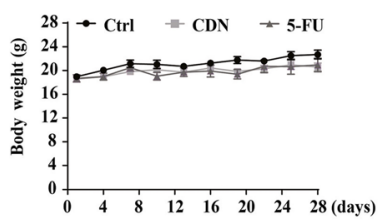

G

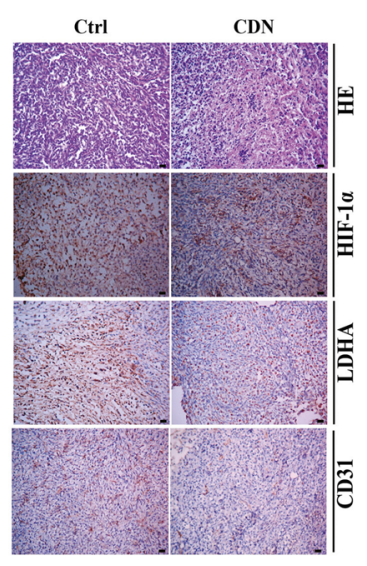

L

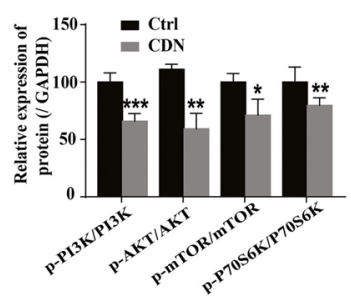

B

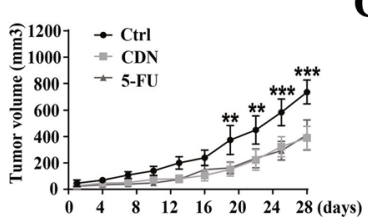

E

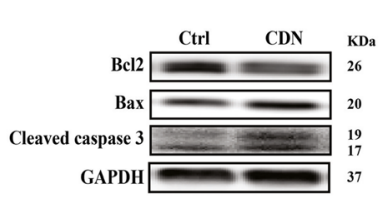

F

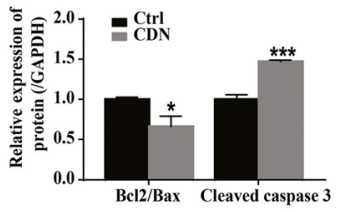

H
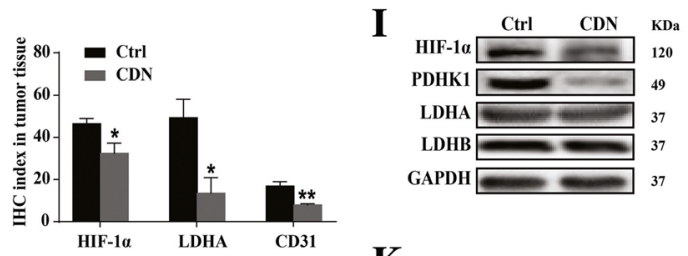

K

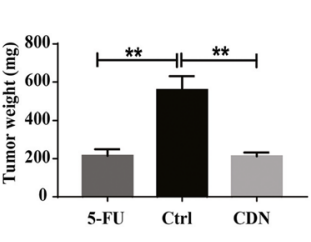

GAPDH

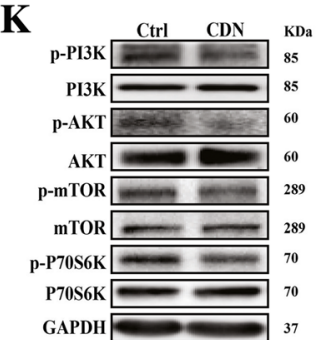

Fig. 7 Cardamon inhibits tumor growth and the protein expression of HIF-1a and its metabolism- related target genes in the MDA-MB-231 xenograft model. a Cardamonin (3 mg/kg) significantly inhibited tumor growth. Scale bar, $10 \mathrm{~mm}$. b Cardamonin $(3 \mathrm{mg} / \mathrm{kg})$ significantly inhibited tumors volume. The size of tumor was measured every three days and calculated according to the formula: [length $\times$ (width) ${ }^{2}$ ]/2. c Cardamonin $(3 \mathrm{mg} / \mathrm{kg}$ ) treatment reduced the tumor weight. $\mathbf{d}$ Cardamonin $(3 \mathrm{mg} / \mathrm{kg}$ ) treatment had little effect on the body weight. e, $\mathbf{f}$ Cardamonin (3 mg/ $\mathrm{kg}$ ) reduced the ratio of $\mathrm{Bc} / 2 / \mathrm{Bax}$ and enhanced protein expression of cleaved caspase 3 in tumor tissues. $\mathbf{g}, \mathbf{h}$ Immunohistochemistry assay data showed that cardamonin (3 mg/kg) inhibited the protein expression of HIF-1a, LDHA and CD31 in tumor tissues (200x). $\mathbf{i}, \mathbf{j}$ Western blotting analysis showed that cardamonin $(3 \mathrm{mg} / \mathrm{kg}$ ) inhibited the protein expression of HIF-1a, PDHK1 and LDHA in tumor tissues. k, I Cardamonin (3 $\mathrm{mg} / \mathrm{kg}$ ) inhibited the protein expression of p-PI3K, p-AKT, p-mTOR and p-p70S6K in tumor tissues. Data are shown as mean $\pm \mathrm{SD} ;{ }^{*}, P<0.05,{ }^{* *}$, $P<0.01 ;{ }^{* * *}, P<0.001$, ns means no statistical difference, compared with control. $n \geq 4$

treatment reduced protein levels of HIF- $1 \alpha$ and LDHA in vivo (Fig. $7 \mathrm{~g}$-j). A reduction in protein levels of p-PI3K, p-AKT, p-mTOR, and p-P70S6K was detected in cardamonin-treated tumor tissues (Fig. $7 \mathrm{k}-1)$. We also found that CD31 staining reduced by $53.10 \%$ in cardamonin-treated breast cancer tissues
(Fig. $7 \mathrm{~g}$ and $\mathrm{h}$ ), suggesting that cardamonin inhibits tumor angiogenesis.

\section{Discussion}

In the present study, we identified novel function of cardamonin in regulating the HIF-1 pathway and 
cancer cell metabolism. We showed that cardamonin treatment reduced HIF- $1 \alpha$ expression in TNBC cell lines, and subsequently inhibited glycolysis and increased mitochondrial OXPHOS and ROS accumulation, finally induced cell apoptosis in breast cancer cells in vitro and in vivo. These results suggest that cardamonin inhibits breast cancer progression by targeting the HIF-1 pathway and its mediated cancer cell metabolism.

ROS is mainly generated during mitochondrial OXPHOS [3, 4], and aerobic glycolysis may reduce ROS accumulation in tumor cells and enhance cancer cell survival during chemotherapy. Integrity of mitochondrial membrane is very important for mitochondrial OXPHOS; disruption of the membrane integrity not only impairs mitochondrial OXPHOS, but also induces cell apoptosis [49-53]. Treatment with cardamonin as late as for $9 \mathrm{~h}$ in breast cancer cells significantly reduced MMP, which was accompanied by a decrease in cell viability. And, enhanced mitochondrial OXPHOS and a reduction in glucose uptake, lactate production and lactate efflux were detected in cardamonin-treated MDA-MB-231 cells as early as for $6 \mathrm{~h}$. These results suggest that cardamonin reduced cell viability by enhancing ROS generation in mitochondria.

Increased levels of ROS have been detected in many cancers, in which they promote tumor development and progression by inducing genome instability and multiple signaling pathways. However, accumulation of ROS to the high level also induces cell apoptosis, suggesting that a delicate balance of intracellular ROS levels is required for cancer cell function [53-55]. Most of the chemotherapeutic drugs and radiotherapy drugs induce cytotoxicity and cell cycle arrest by increasing oxidative stress [56-60]. We identified cardamonin as a ROS inducer in breast cancer cells. Cardamonin increased ROS at least partially through reducing the ROS scavenging system because Nrf2 and NQO1 expression is reduced upon treatment. Importantly, NAC, the active oxygen scavenger, reversed the inhibitory effect of cardamonin on cell viability in breast cancer cells. These results suggest that ROS is the critical mediator of inhibitory function of cardamonin in breast cancer cells.

Tumor recurrence and metastasis are major challenges in the treatment of tumors. Accumulation of lactate acid induced by glycolysis, which acidifies the tumor microenvironment and subsequently promotes tumor metastasis [60]. It has been shown that reduction of lactate acid level slowed down or even block cancer metastasis $[60,61]$. We found that the lactate acid efflux was inhibited by cardamonin, implicating a potential function of cardamonin in suppressing cancer metastasis. Indeed, our unpublished data showed that cardamonin treatment inhibit breast cancer metastasis in vitro.

HIF- $1 \alpha$ is a crucial regulator of cell metabolism by modulating glycolytic enzyme gene expression [12, 62, $63]$. At the low level of HIF- $1 \alpha$, pyruvate, one of the end products of glycolysis, is mainly converted into acetyl$\mathrm{CoA}$ and enters the citric acid cycle. However, the majority of pyruvate enters aerobic glycolysis when the HIF-1 pathway is activated. This regulation is mainly through PDHK1, a gene inhibiting PDH activity to reduce the entrance of acetyl-CoA into citric acid cycle $[12,62]$. We found that cardamonin treatment decreased the mRNA and protein expressions of HIF- $1 \alpha$ and inhibited its target genes in MDA-MB-231 and BT549 cells. Rescue experiments showed that introduction of HIF- $1 \alpha$ and PDHK1 prevented the increase of mitochondrial OXPHOS and ROS accumulation induced by cardamonin. Together these results indicate that cardamonin inhibits cancer growth at least partially through targeting HIF-1 $\alpha$-mediated metabolic reprogramming in TNBC cells. In ER positive MCF7 cells, cardamonin failed to reduce protein levels of HIF- $1 \alpha$, but the protein expression of PDHK1 was still inhibited by cardamonin. However, PDHK1 overexpression or NAC both abolished the inhibitory effect of cardamonin on cell viability in MCF7 cells, suggesting that other molecular mechanisms are involved in PDHK1 regulation and metabolic reprogramming in MCF7 cells.

It has been shown that the mTOR/p70S6K pathway [19], NF- $\kappa B$ pathway [64, 65] and MAPK pathway [66, 67] regulate the HIF-1 pathway during cancer progression [68-70]. Our study showed that cardamonin inhibited activation of the mTOR/p70S6K pathway in MDAMB-231 cells. Rescue experiments demonstrated that mTOR activation abolished the inhibitory activity of cardamonin on the cell viability and protein expression of HIF- $1 \alpha$ and PDHK1 in MDA-MB-231 cells. Given roles of the NF- $\mathrm{kB}$ pathway in enhancing cell survival and HIF-1 activation, we also determined whether NF$\kappa \mathrm{B}$ mediates function of cardamonin in breast cancer cells. We found that cardamonin treatment reduced $\mathrm{p}$ NF- $\mathrm{kB}$ levels at very early time point (Additional file 1 : Figure S4). Interestingly, TNF- $\alpha$ (agonist of NF- $к B$ ) pretreatment reversed the inhibitory effect of cardamonin on cell viability and protein levels of p-NF-kB, HIF- $1 \alpha$ and PDHK1 in MDA-MB-231 cells. This results suggest that the NF- $\mathrm{KB}$ pathway is another potential target of cardamonin that regulates HIF-1 $\alpha /$ PDHK1 axis in breast cancer cells.

\section{Conclusions}

Our results reveal novel function of cardamonin in inhibiting the HIF- $1 \alpha$ pathway and its dependent metabolic 


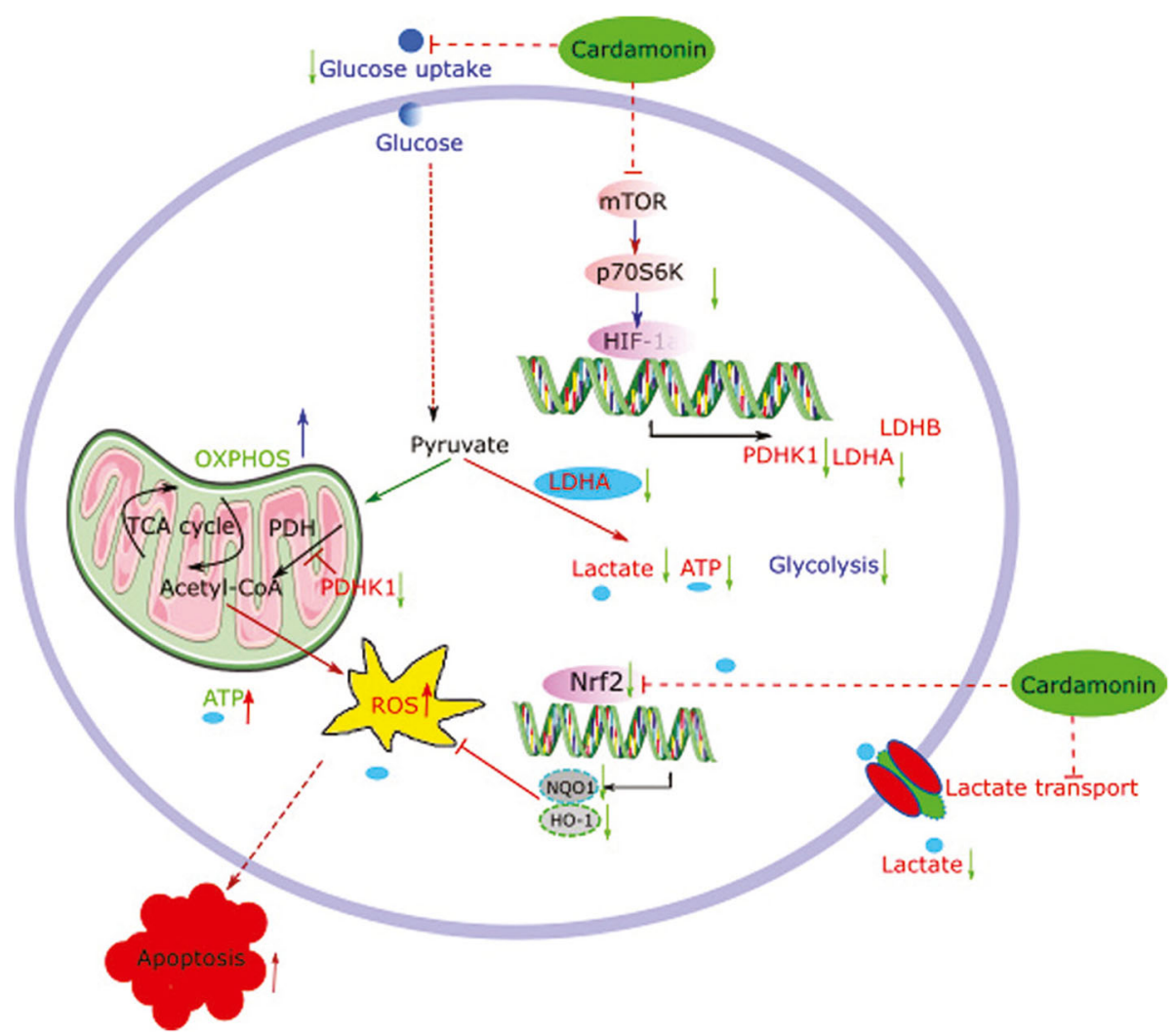

Fig. 8 Schematic representation of possible molecular mechanism by which cardamonin represses HIF-1a-dependent metabolic reprogramming and inhibits breast cancer growth

reprogramming in breast cancer cells (Fig. 8). We also identified the mTOR/p70S6K pathway as one of the cardamonin targets to repress HIF-1 $\alpha /$ PDHK1 axis. These findings provide the mechanistic insight into tumor inhibitory activity of cardamonin and suggest the therapeutic potential of cardamonin in breast cancer treatment.

\section{Additional file}

Additional file 1 : Figure S1. Cardamonin inhibited cell viability of BT549 and MCF7 cells. Figure S2. Cardamonin regulated cancer metabolism and Nrf2 mediated antioxidant system in BT549 and MCF7 cells early before cell death. Figure S3. Cardamonin regulated HIF-1a/ PDHK1 axis in BT549 and MCF7 cells. Figure S4. Cardamonin prevented the overactivation of NF-KB in MDA-MB-231 cells. (PDF 659 kb)

\section{Abbreviations}

Akt: Protein kinase B, PKB; ATP: Adenosine triphosphate; $\mathrm{CoCl}_{2}$ : Cobaltchloride; Compensatory: Compensatory glycolysis; DCFH-DA: 2',7'Dichlorodihydrofluorescein; ECAR: Extracellular acidification rate; elF4E: Eukaryotic initiation factor 4E; GLUTs: Glucose transporters; Glyco: Glycolysis; GlycoPER: Glycolytic proton efflux rate; HIF-1a: Hypoxiainducible factor-1a; HO-1: Heme oxygenase-1; LDH: Lactate dehydrogenase; MCTs: Monocarboxylate transporters; MMP: Mitochondrial membrane potential; mTOR: Mammalian target of rapamycin; NAC: N-acetyl-L-cysteine; NQO1: NAD(P)H: quinone oxidoreductase 1; Nrf2: NF-E2-related factor 2; OCR: Oxygen consumption rate; OXPHOS: Mitochondrial oxidative phosphorylation; PDHK1: Pyruvate dehydrogenase kinase 1; PER: Proton efflux rate; PI3K: Phosphatidylinositol-3- kinase; PPP: Pentose phosphate pathway; ROS: Reactive oxygen species

\section{Acknowledgements}

This work was supported by the National Natural Science Foundation of China (81603354), Shanghai Eastern Scholar Program (2013-59), Shanghai Eresearch Institute of Bioactive Constituent in TCM plan.

\section{Authors' contributions}

$J J$ and SQ did most of experiments and wrote the original draft. PW took part in finishing cell metabolism assays. XL took part in cell culture and western blot assay. FH took part in Hoechst staining assay. HW supported to optimize experimental protocols. BZ took part in in vivo study. WZ provided valuable suggestions and helped revise the manuscript. XT took part in ROS measurement. RX designed experiments and helped revise the manuscript. HS designed experiments and write the manuscript. XW designed experiments and helped revise the manuscript. All authors read and approved the final manuscript.

\section{Funding}

This work was supported by the National Natural Science Foundation of China (81603354), Shanghai Eastern Scholar Program (2013-59), Shanghai Eresearch Institute of Bioactive Constituent in TCM plan.

\section{Availability of data and materials}

All data that can prove the conclusion of this article are included in the article.

\section{Ethics approval and consent to participate}

All animal experiments were carried out in accordance with the protocol approved by the Animal Ethics Committee in Shanghai University of Traditional Chinese Medicine (SHUTCM), which complies with international rules and policies for laboratory animal use and care as founded in the 
European Community guidelines (EEC Directive of 1986; 86/609/EEC). All animal experiments were approved by the institutional Ethics Committee of SHUTCM (SZY201704012).

\section{Consent for publication}

Not applicable.

\section{Competing interests}

The authors declare that they have no competing interests.

\section{Author details}

'Shanghai Key Laboratory of Compound Chinese Medicines, Institute of Chinese Materia Medica, Shanghai University of Traditional Chinese Medicine, 1200 Cailun Road, Zhangjiang Hi-tech Park, Shanghai 201203, China. ${ }^{2}$ Markey Cancer Center, Department of Pharmacology and Nutritional Sciences, University of Kentucky College of Medicine, Biopharm 553, 789 S. Limestone, Lexington, KY 40536, USA. Institute of Interdisciplinary Integrative Medicine Sciences, Shanghai University of Traditional Chinese Medicine, Shanghai 201203, China

Received: 28 March 2019 Accepted: 29 July 2019

Published online: 27 August 2019

\section{References}

1. Siegel RL, Miller KD, Jemal A. Cancer statistics, 2019. CA Cancer J Clin. 2019; $69: 7-34$

2. Liu S, Guan SW, Wu DY, Dong M. Literature analysis of adverse drug reactions induced by tumor molecular-targeted drugs. Chin Pharm. 2014;38: 3613-366 (In Chinese).

3. Starkov AA. The role of mitochondria in reactive oxygen species metabolism and signaling. Ann N Y Acad Sci. 2008;1147:37-52.

4. Al-Gubory KH, Fowler PA, Garrel C. The roles of cellular reactive oxygen species, oxidative stress and antioxidants in pregnancy outcomes. Int $J$ Biochem Cell Biol. 2010;42:1634-50.

5. Li H, Wang P, Huang F, Jin J, Wu H, Zhang B, et al. Astragaloside IV protects blood-brain barrier integrity from LPS-induced disruption via activating Nrf2 antioxidant signaling pathway in mice. Toxicol Appl Pharmacol. 2018;340: 58-66.

6. Hanahan D, Weinberg RA. Hallmarks of cancer: the next generation. Cell. 2011;144:646-74.

7. Gatenby RA, Gillies RJ. Why do cancers have high aerobic glycolysis? Nat Rev Cancer. 2004;4:891-9.

8. Morais-Santos F, Granja S, Miranda-Gonçalves V, Moreira AH, Queirós S, Vilaça JL, et al. Targeting lactate transport suppresses in vivo breast tumour growth. Oncotarget. 2015;6:19177-89.

9. Wu Y, Sarkissyan M, Mcghee E, Lee S, Vadgama JV. Combined inhibition of glycolysis and AMPK induces synergistic breast cancer cell killing. Breast Cancer Res Treat. 2015;151:529-39.

10. Ganapathy-Kanniappan S. Molecular intricacies of aerobic glycolysis in cancer: current insights into the classic metabolic phenotype. Crit Rev Biochem Mol Biol. 2018;53:667-82.

11. Zhao Y, Hu X, Liu Y, Dong S, Wen Z, He W, et al. ROS signaling under metabolic stress: cross-talk between AMPK and AKT pathway. Mol Cancer. 2017;16:79.

12. Singh D, Arora R, Kaur P, Singh B, Mannan R, Arora S, et al. Overexpression of hypoxia-inducible factor and metabolic pathways: possible targets of cancer. Cell Biosci. 2017;7:62.

13. Cesi G, Walbrecq G, Zimmer A, Kreis S, Haan C. ROS production induced by BRAF inhibitor treatment rewires metabolic processes affecting cell growth of melanoma cells. Mol Cancer. 2017;16:102.

14. Denko NC. Hypoxia, HIF1 and glucose metabolism in the solid tumour. Nat Rev Cancer. 2008;8:705-13.

15. Koukourakis MI, Giatromanolaki A, Sivridis E, Gatter KC, Harris AL, Tumor and Angiogenesis Research Group. Pyruvate dehydrogenase and pyruvate dehydrogenase kinase expression in non small cell lung cancer and tumorassociated stroma. Neoplasia. 2005;7:1-6.

16. Ullah MS, Davies AJ, Halestrap AP. The plasma membrane lactate tranporter MCT4, but not MCT1, is up-regulated by hypoxia through a HIF-1adependent mechanism. J Biol Chem. 2006;281:9030-7.

17. Gingras AC, Raught $B$, Sonenberg N. Regulation of translation initiation by FRAP/mTOR. Genes Dev. 2001;15:807-26.
18. Pore N, Jiang Z, Shu HK, Bernhard E, Kao GD, Maity A, et al. Akt1 activation can augment hypoxia-inducible factor-1a expession by increasing protein translation through a mammalian target of rapamycin-independent pathway. Mol Cancer Res. 2006:4:471-9.

19. Di Conza G, Trusso Cafarello S, Loroch S, Mennerich D, Deschoemaeker S, Di Matteo M, et al. The mTOR and PP2A pathways regulate PHD2 phosphorylation to fine-tune HIF1a levels and colorectal Cancer cell survival under hypoxia. Cell Rep. 2017;18:1699-712.

20. Pouysségur J, Dayan F, Mazure NM. Hypoxia signalling in cancer and approaches to enforce tumour regression. Nature. 2006;441:437-43.

21. Ravi R, Mookerjee B, Bhujwalla ZM, Sutter CH, Artemov D, Zeng Q, et al. Regulation of tumor angiogenesis by p53-induced degradation of hypoxiainducible factor 1a. Genes Dev. 2000;14:34-44.

22. James S, Aparna JS, Paul AM, Lankadasari MB, Mohammed S, Binu VS, et al. Cardamonin inhibits colonic neoplasia through modulation of MicroRNA expression. Sci Rep. 2017;7:13945

23. Yadav VR, Prasad S, Aggarwal BB. Cardamonin sensitizes tumour cells to TRAIL through ROS- and CHOP-mediated up-regulation of death receptors and down-regulation of survival proteins. Br J Pharmacol. 2012;165:741-53.

24. Jia D, Yang W, Li L, Liu H, Tan Y, Ooi S, et al. Beta-catenin and NF-kappaB co-activation triggered by TLR3 stimulation facilitates stem cell-like phenotypes in breast cancer. Cell Death Differ. 2015;22:298-310.

25. Li Y, Qin Y, Yang C, Zhang H, Li Y, Wu B, et al. Cardamonin induces ROSmediated G2/M phase arrest and apoptosis through inhibition of NF-KB pathway in nasopharyngeal carcinoma. Cell Death Dis. 2017;8:e3024.

26. Jia D, Tan Y, Liu H, Ooi S, Li L, Wright K, et al. Cardamonin reduces chemotherapy-enriched breast cancer stem-like cells in vitro and in vivo. Oncotarget. 2016;7:771-85.

27. Lu S, Lin C, Cheng $X$, Hua H, Xiang T, Huang $Y$, et al. Cardamonin reduces chemotherapy resistance of colon cancer cells via the TSP50/NF-kappaB pathway in vitro. Oncol Lett. 2018;15:9641-6.

28. Park S, Gwak J, Han SJ, Oh S. Cardamonin suppresses the proliferation of colon cancer cells by promoting beta-catenin degradation. Biol Pharm Bull. 2013;36:1040-4.

29. Shrivastava S, Jeengar MK, Thummuri D, Koval A, Katanaev VL, Marepally $\mathrm{S}$, et al. Cardamonin, a chalcone, inhibits human triple negative breast cancer cell invasiveness by downregulation of Wnt/beta-catenin signaling cascades and reversal of epithelial-mesenchymal transition. Biofactors. 2017;43:152-69.

30. He W, Jiang $Y$, Zhang $X$, Zhang $Y$, Ji H, Zhang N. Anticancer cardamonin analogs suppress the activation of NF-kappaB pathway in lung cancer cells. Mol Cell Biochem. 2014;389:25-33.

31. Niu P, Shi D, Zhang S, Zhu Y, Zhou J. Cardamonin enhances the antiproliferative effect of cisplatin on ovarian cancer. Oncol Lett. 2018;15:3991-7.

32. Hou G, Yuan X, Li Y, Hou G, Liu X. Cardamonin, a natural chalcone, reduces 5 -fluorouracil resistance of gastric cancer cells through targeting Wnt/Bcatenin signal pathway. Investig New Drugs. 2019. https://doi.org/10.1007/ s10637-019-00781-9.

33. Cheng $C$, Q Q Y, Wang YC, Chi KK, Chung Y, Ouyang C, et al. Arginine starvation kills tumor cells through aspartate exhaustion and mitochondrial dysfunction. Commun Biol. 2018;1:178.

34. Li Q, Ma R, Zhang M. CoCl 2 increases the expression of hypoxic markers HIF-1alpha, VEGF and CXCR4 in breast cancer MCF-7 cells. Oncol Lett. 2018; 15:1119-24.

35. Zhang E, Shi H, Yang L, Wu X, Wang Z. Ginsenoside Rd regulates the Akt/ mTOR/p70S6K signaling cascade and suppresses angiogenesis and breast tumor growth. Oncol Rep. 2017;38:359-67.

36. Wang Q, Huang J, Ma K, Li T, Chen M, Wang S, et al. Evaluation of ghost cell survival in the area of radiofrequency ablation. PLoS One. 2012;7:e53158,

37. Shi J, Qu Y, Li X, Sui F, Yao D, Yang Q, et al. Increased expression of EHF via gene amplification contributes to the activation of HER family signaling and associates with poor survival in gastric cancer. Cell Death Dis. 2016;7:e2442.

38. Szafarowski T, Sierdzinski J, Szczepanski MJ, Whiteside TL, Ludwig N, Krzeski $\mathrm{A}$, et al. Microvessel density in head and neck squamous cell carcinoma. Eur Arch Otorhinolaryngol. 2018;275:1845-51.

39. Paradiso A, Scarpi E, Malfettone A, Addati T, Giotta F, Simone G, et al. Nuclear NHERF1 expression as a prognostic marker in breast cancer. Cell Death Dis. 2013:4:e904.

40. Lei Z, Duan H, Zhao T, Zhang Y, Li G, Meng J, et al. PARK2 inhibits osteosarcoma cell growth through the JAK2/STAT3/NEGF signaling pathway. Cell Death Dis. 2018;9:375. 
41. Shi HL, Liu CH, Ding LL, Zheng Y, Fei XY, Lu L, et al. Alterations in serotonin, transient receptor potential channels and protease-activated receptors in rats with irritable bowel syndrome attenuated by Shugan decoction. World J Gastroenterol. 2015;21:4852-63.

42. Xiong G, Stewart RL, Chen J, Gao T, Scott TL, Samayoa LM, et al. Collagen prolyl 4-hydroxylase 1 is essential for HIF-1a stabilization and TNBC chemoresistance. Nat Commun. 2018;9:4456.

43. Semenza GL. Molecular mechanisms mediating metastasis of hypoxic breast cancer cells. Trends Mol Med. 2012:18:534-43.

44. Generali D, Berruti A, Brizzi MP, Campo L, Bonardi S, Wigfield S, et al. Hypoxia-inducible factor-1alpha expression predicts a poor response to primary chemoendocrine therapy and disease-free survival in primary human breast cancer. Clin Cancer Res. 2006:12:4562-8.

45. Kensler TW, Wakabayashi N, Biswal S. Cell survival responses to environmental stresses via the Keap1-Nrf2-ARE pathway. Annu Rev Pharmacol Toxicol. 2007;47:89-116.

46. Wei Y, Gong J, Xu Z, Thimmulappa RK, Mitchell KL, Welsbie DS, et al. Nrf2 in ischemic neurons promotes retinal vascular regeneration through regulation of semaphorin 6A. Proc Natl Acad Sci U S A. 2015:112:6927-36.

47. McSweeney SR, Warabi E, Siow RC. Nrf2 as an endothelial mechanosensitive transcription factor: going with the flow. Hypertension. 2016;67:20-9.

48. Shang Y, Zhou Q, Wang T, Jiang Y, Zhong Y, Qian G, et al. Airborne nitroPAHs induce Nrf2/ARE defense system against oxidative stress and promote inflammatory process by activating PI3K/Akt pathway in A549 cells. Toxicol in Vitro. 2017:44:66-73.

49. Previte DM, O'Connor EC, Novak EA, Martins CP, Mollen KP, Piganelli JD. Reactive oxygen species are required for driving efficient and sustained aerobic glycolysis during CD4+ T cell activation. PLoS One. 2017;12 e0175549.

50. Qin W, Li C, Zheng W, Guo Q, Zhang Y, Kang M, et al. Inhibition of autophagy promotes metastasis and glycolysis by inducing ROS in gastric cancer cells. Oncotarget. 2015;6:39839-54.

51. Wang M, Ruan Y, Chen Q, Li S, Wang Q, Cai J. Curcumin induced HepG2 cell apoptosis-associated mitochondrial membrane potential and intracellular free ca (2+) concentration. Eur J Pharmacol. 2011;650:41-7.

52. Chen $P$, Zhang JY, Sha BB, Ma YE, Hu T, Ma YC, et al. Luteolin inhibits cell proliferation and induces cell apoptosis via down-regulation of mitochondrial membrane potential in esophageal carcinoma cells EC1 and KYSE450. Oncotarget. 2017:8:27471-80.

53. Leanza L, Romio M, Becker KA, Azzolini M, Trentin L, Managò A, et al. Direct pharmacological targeting of a mitochondrial ion channel selectively kills tumor cells in vivo. Cancer Cell. 2017;31:51631.e10.

54. Panieri E, Santoro MM. ROS homeostasis and metabolism: a dangerous liason in cancer cells. Cell Death Dis. 2016;7:e2253.

55. Pelicano H, Carney D, Huang P. ROS stress in cancer cells and therapeutic implications. Drug Resist Updat. 2004;7:97-110.

56. Che Y, Wang J, Yuan Z, Li Y, Lu Z, Zhang Z, et al. The therapeutic effects of Longikaurin a, a natural ent-kauranoid, in esophageal squamous cell carcinoma depend on ROS accumulation and JNK/p38 MAPK activation. Toxicol Lett. 2017;280:106-15.

57. Hu J, Li H, Luo X, Li Y, Bode A, Cao Y, et al. The role of oxidative stress in EBV lytic reactivation, radioresistance and the potential preventive and therapeutic implications. Int J Cancer. 2017;141:1722-9.

58. Kroemer G, Reed JC. Mitochondrial control of cell death. Nat Med. 2000;6: 513-9.

59. Kroemer G, Dallaporta B, Resche-Rigon M. The mitochondrial death/life regulator in apoptosis and necrosis. Annu Rev Physiol. 1998;60:619-42.

60. Haugrud AB, Zhuang Y, Coppock JD, Miskimins WK. Dichloroacetate enhances apoptotic cell death via oxidative damage and attenuates lactate production in metformin-treated breast cancer cells. Breast Cancer Res Treat. 2014;147:539-50

61. Harmon C, Robinson MW, Hand F, Almuaili D, Mentor K, Houlihan DD, et al. Lactate-mediated acidification of tumor microenvironment induces apoptosis of liver-resident NK cells in colorectal liver metastasis. Cancer Immunol Res. 2019;7:335-46.

62. Kim JW, Tchernyshyov I, Semenza GL, Dang CV. HIF-1-mediated expression of pyruvate dehydrogenase kinase: a metabolic switch required for cellular adaptation to hypoxia. Cell Metab. 2006;3:177-85.

63. Lu H, Forbes RA, Verma A. Hypoxia-inducible factor 1 activation by aerobic glycolysis implicates the Warburg effect in carcinogenesis. J Biol Chem. 2002;277:23111-5
64. Jiang Y, Zhu Y, Wang X, Gong J, Hu C, Guo B, et al. Temporal regulation of HIF-1 and NF-kB in hypoxic hepatocarcinoma cells. Oncotarget. 2015;6: 9409-19.

65. Sung WW, Chu YC, Chen PR, Liao MH, Lee JW. Positive regulation of HIF-1A expression by EBV oncoprotein LMP1 in nasopharyngeal carcinoma cells. Cancer Lett. 2016;382:21-31.

66. Li Z, Ya K, Xiao-Mei W, Lei Y, Yang L, Ming QZ. Ginkgolides protect PC12 cells against hypoxia-induced injury by p42/p44 MAPK pathway-dependent upregulation of HIF-1alpha expression and HIF-1DNA-binding activity. J Cell Biochem. 2008;103:564-75.

67. Mylonis I, Chachami G, Samiotaki M, Panayotou G, Paraskeva E, Kalousi A, et al. Identification of MAPK phosphorylation sites and their role in the localization and activity of hypoxia-inducible factor-1alpha. J Biol Chem. 2006;281:33095-106

68. Zhang $X$, Chen J, Ai Z, et al. Targeting glycometabolic reprogramming to restore the sensitivity of leukemia drug-resistant K562/ADM cells to adriamycin. Life Sci. 2018;215:1-10.

69. Masui K, Tanaka K, Akhavan D, et al. mTOR complex 2 controls glycolytic metabolism in glioblastoma through FoxO acetylation and upregulation of c-Myc. Cell Metab. 2013;18:726-39.

70. Allen-Petersen BL, Risom T, Feng Z, et al. Activation of PP2A and inhibition of mTOR synergistically reduce MYC signaling and decrease tumor growth in pancreatic ductal adenocarcinoma. Cancer Res. 2019;79:209-19.

\section{Publisher's Note}

Springer Nature remains neutral with regard to jurisdictional claims in published maps and institutional affiliations.

\section{Ready to submit your research? Choose BMC and benefit from:}

- fast, convenient online submission

- thorough peer review by experienced researchers in your field

- rapid publication on acceptance

- support for research data, including large and complex data types

- gold Open Access which fosters wider collaboration and increased citations

- maximum visibility for your research: over $100 \mathrm{M}$ website views per year

At $\mathrm{BMC}$, research is always in progress.

Learn more biomedcentral.com/submissions 